\title{
A Case of Takotsubo Cardiomyopathy due to Submucosal Epinephrine Injection during Endoscopic Sinus Surgery
}

\author{
Min Ju Park ${ }^{1}$, Byung Hoon Ahn ${ }^{1}$, Se Young Kim ${ }^{2}$ and Dong Eun Kim ${ }^{1}$ \\ ${ }^{1}$ Departments of Otorhinolaryngology, ${ }^{2}$ Anesthesiology and Pain Medicine, School of Medicine, Keimyung University, Daegu, Korea
}

\section{부비동 내시경 수술 중 Epinephrine 국소주사 후 발생한 Takotsubo 심근병증 1예}

박민주 ${ }^{1} \cdot$ 안병훈 $^{1} \cdot$ 김세영 ${ }^{2} \cdot$ 김동은 $^{1}$

계명대학교 의과대학 이비인후과학교실, ${ }^{1}$ 마취통증의학교실 ${ }^{2}$

\author{
Received January 31,2013 \\ Revised March 29, 2013 \\ Accepted April 1, 2013 \\ Address for correspondence \\ Dong Eun Kim, MD, PhD \\ Department of Otorhinolaryngology, \\ School of Medicine, \\ Keimyung University, \\ 56 Dalseong-ro, Jung-gu, \\ Daegu 700-712, Korea \\ Tel $+82-53-250-7757$ \\ Fax $+82-53-256-0325$ \\ E-mail entkde@dsmc.or.kr
}

Epinephrine is widely used for hemostasis during endoscopic sinus surgery performed under local and general anesthesia. However, topical epinephrine can cause many adverse effects, such as hypertension, ventricular tachycardia, pulmonary edema and cardiac arrest. Takotsubo cardiomyopathy is a newly described clinical entity characterized by transient left ventricular dysfunction and no significant coronary artery stenosis. We experienced a rare case of reversible Takotsubo cardiomyopathy in a 56-year-old male after submucosal epinephrine injection with an appropriate dose during an endoscopic sinus surgery.

Korean J Otorhinolaryngol-Head Neck Surg 2013;56:317-21

Key Words Epinephrine - Takotsubo cardiomyopathy.

\section{서 론}

Epinephrine은 혈관 수축 작용이 있어 이비인후과 영역의 수술에서 출혈을 줄이고, 국소 마취제의 전신적 흡수를 막기 위해 국소 침윤 또는 점막 도포의 방법으로 널리 사용되고 있 다. 그러나 epinephrine은 과량을 사용하거나 혈관에 직접 주 사하면 치명적인 심계항진, 폐부종, 심정지 등의 심각한 부작 용을 초래할 수 있다. ${ }^{1)}$ 그런데 수술 중 허용 범위내의 epinephrine을 국소적으로 사용한 후 급성 심근경색증과 유사한 양 상을 나타내는 Takotsubo 심근병증이 드물게 보고되고 있다. ${ }^{2)}$ 이 질환은 급성기에 응급 처치가 제대로 이루어지면 정상 상 태로 회복이 가능하지만 치료시기를 놓치면 폐부종, 심정지까 지 일으킬 수 있다. ${ }^{3)}$ 저자들은 만성 부비동염으로 내원한 56세 남자 환자의 부비동 내시경 수술 중 허용 범위 안의 epinephrine을 비점막하 국소 주사 후 발생한 가역적인 Takotsubo 심
근병증 1 예를 경험하였기에 문헌 고찰과 함께 보고하는 바이다.

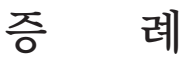

56세 남자 환자가 수년간 반복되는 양측 비강의 비폐색 및 후비루를 주소로 내원하였다. 환자의 신장은 $160 \mathrm{~cm}$, 체중은 $70 \mathrm{~kg}$ 이었고, 30 년간 하루 1 갑의 흡연력이 있었다. 내원 3년 전 고혈압 진단을 받고 항고혈압 약물을 복용 중이었다. 내원 당 시 시행한 비내시경 검사 상 우측 비강 내에 용종이 관찰되고, 부비동 전산화단층촬영 검사 상 우측 상악동과 사골동에 부 비동염이 의심되어 전신마취 하 부비동 내시경 수술을 계획하 였다. 수술 전 시행한 단순 흥부 촬영, 혈액 검사에서 특이 소 견은 보이지 않았지만, 심전도 검사에서는 QRS 확장 소견 및 좌심실 비대 소견을 보였다(Fig. 1A). 술 전 심전도 이상 소견과 고혈압 기왕력을 주소로 심장내과에 협진을 의뢰하였고, 그 결 
과 허혈성 심질환을 의심할 만한 당시의 급성 증상이 없고, 혈 압 조절이 잘된 점, 그리고 $\mathrm{QRS}$ 확장이 저명하지 않은 점 등을 고려하여 수술의 고위험군은 아니라는 결과를 통보 받아 예정 대로 수술을 진행하게 되었다. 마취 전 처치로 진통제인 meperidine $30 \mathrm{mg}$ 과 항콜린제인 glycopyrrolate $2 \mathrm{mg}$ 을 수술 30 분 전 근주하였다. 수술실 도착 당시 혈압은 $120 / 70 \mathrm{~mm} \mathrm{Hg}$, 심박수 100회/분, 산소포화도는 99\%로 측정되었다. 정맥 마 취제인 propofol $120 \mathrm{mg}$ 을 정주한 후 $100 \%$ 산소를 마스크 로 투여하면서 마취를 유도하였다. 근이완제인 esmeron 50 $\mathrm{mg}$ 으로 근육 이완을 확인한 후 기관 내 삽관을 시행하였다. 기 관 삽관 전후 활력 징후의 이상 소견은 없었다. $1.5 \mathrm{~L} / \mathrm{min}$ 의 산소 및 아산화질소와 흡입마취제인 desflurane $2.0 \mathrm{vol} \%$ 로 마취를 유지하였다. 마취 유도 후 혈압은 $120 / 80 \mathrm{~mm} \mathrm{Hg}$, 심박 수 120회/분, 산소 포화도는 99\%를 유지하였다. 마취 시작 5 분 후 수술이 시작되었고, 점막 수축을 통해 수술 시야를 좋게 하기 위해 증류수에 희석된 $1: 100000$ epinephrine을 거즈 에 적셔 우측 비강에 삽입하였다. 약 5 분 후 거즈를 제거하였 고, 이때까지 활력 징후의 변화는 없었다. 곧이어 $1: 100000$ 농도의 epinephrine이 혼합된 $1 \%$ lidocaine $5 \mathrm{~mL}$ 를 혈액 음 성을 확인한 후 접형구개동맥과 전사골동 동맥 유입 부위와 구상 돌기 부위의 점막에 국소 침윤하였다. 주사 약 3 분 후 갑 자기 혈압이 220/130 mm Hg까지 상승하고, 맥박은 140회로 증가하였다. 곧이어 심전도 상 심실 조기 수축이 나타나 수술 을 중단하고, 항부정맥 약제인 lidocaine $50 \mathrm{mg}$ 을 주사하였
다. 약 3 분 후 혈압이 90/50 mm Hg까지 떨어진 다음 갑자기 혈압이 측정되지 않았다. 심전도 상 ST-분절 상승이 나타난 후 심실성 빈맥 소견을 보여 모든 마취약제 투여를 중단하고 흥 부 압박을 시행하였다. Epinephrine과 atropine을 정맥 주사 하면서 약 3분간 심폐 소생술을 시행하자 심실성 율동에서 동 율동으로 회복되었다. 혈압은 $150 / 100 \mathrm{~mm} \mathrm{Hg}$ 까지 상승하였 고, 심박동수는 분당 90 회로 측정되었다. 산소 계측기에 의한 산소포화도는 $85 \%$ 로 측정되었으나 더 이상 상승하지 않았다. 환자가 의식을 회복하지 못해 기관 삽관을 유지한 상태로 중 환자실로 이송하여 기계적 환기를 시행하였다. 기관 내 튜브에 서는 붉은색 거품이 섞인 분비물이 배출되었고, 흥부 방사선 촬영 상 양측 폐 영역의 혼탁상이 관찰되어 폐부종 의심 하에 이뇨제를 투여하였다(Fig. 2A). 중환자실에서 시행한 심전도 검사 상에서는 II, III, aVF lead에서 ST-분절의 하강이 관찰 되었고(Fig. 1B), 혈액 검사 상 troponin-I가 $0.35 \mathrm{ng} / \mathrm{mL}$ 로 증 가되어 있었다. 중환자실에서 심근병증 발병 당일 시행한 경 흥부 심초음파 소견 상 경미한 좌심실 운동 저하와 좌심실 중 벽 및 기저부의 무운동으로 의심되는 양상을 관찰할 수 있었 고(Fig. 3), 심박출 계수는 $44 \%$ 를 나타내었다. 환자는 중환자실 에 입실한지 3 시간 만에 의식을 회복하여 기관 내 삽관을 제거 하였다. 심근병증 발병 1 일째 강심제나 승압제를 중단한 이후 에도 활력 징후는 안정 상태를 유지하였다. 발병 2일째 시행한 심장 혈관 조영술 상 폐쇄 소견 없이 정상적인 혈관 조영상을 보였다(Fig. 4). 이후 지속적으로 안정된 활력 징후를 보여, 발

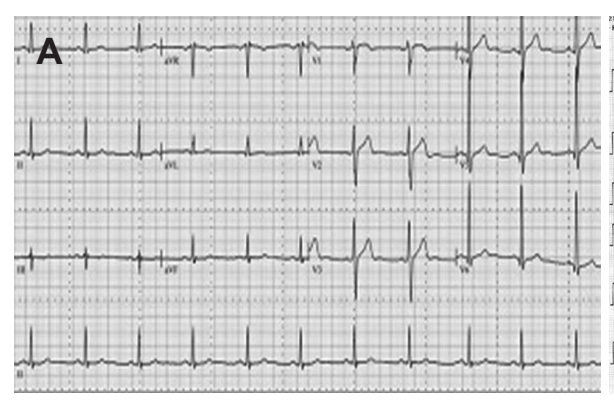

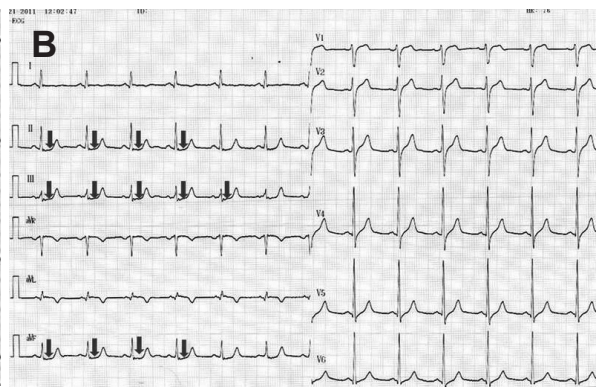

Fig. 1. Perioperative electrocardiography. The pre-operative reveals normal sinus rhythm and left ventricular hypertrophy with QRS widening (A). The post-operative electrocardiogram reveals significant ST depression in leads II, III, aVF (arrow)(B).
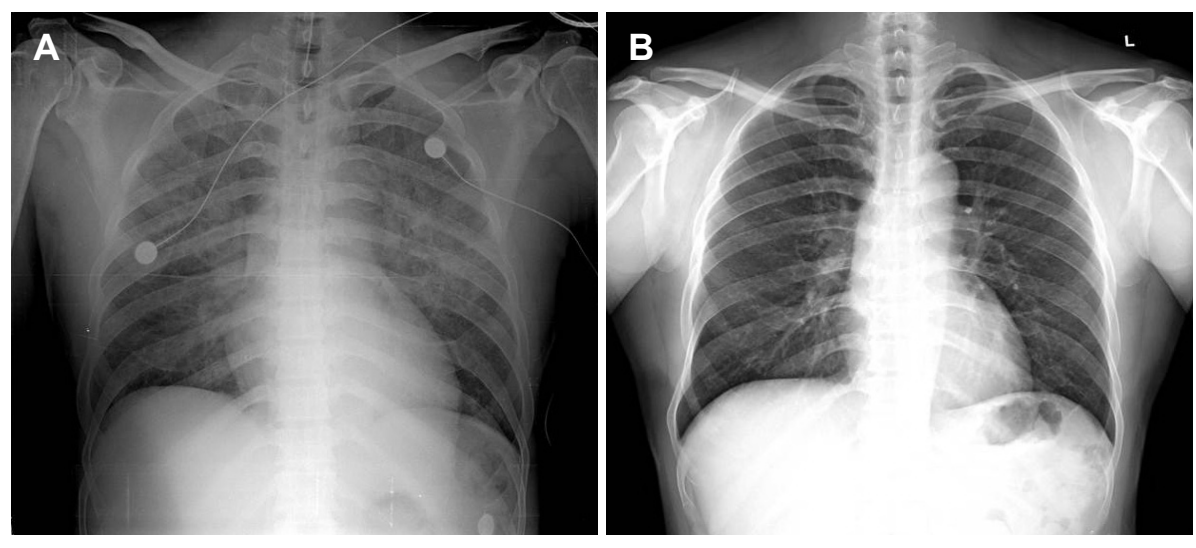

Fig. 2. Post-operative chest radiography (AP) shows hazy density at both lung (A). After operative 5 days, chest radiography $(\mathrm{PA})$ shows normal findings (B). AP: anteroposterior view, $\mathrm{PA}$ : posteroanterior view. 

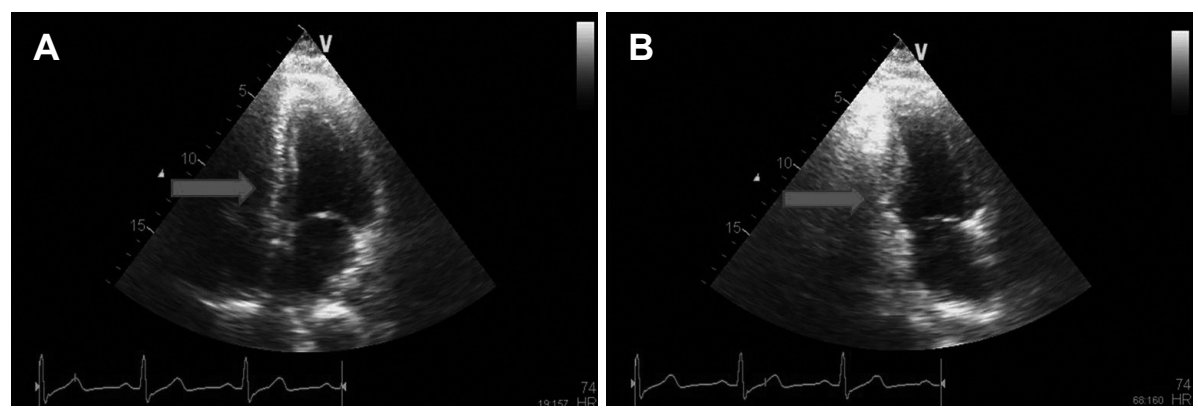

Fig. 3. The transthoracic echocardiography reveals mild akinesia of the basal and mid portion of left ventricle. Apical 4-chamber view (A). Apical 2chamber view $(\mathrm{B})$.
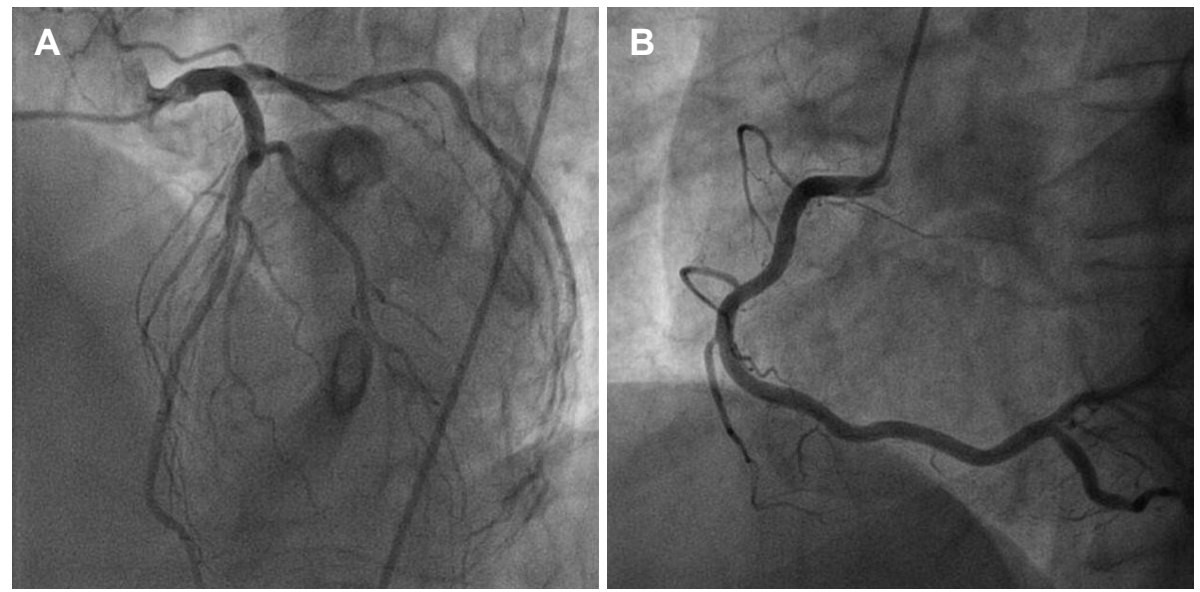

Fig. 4. Coronary angiogram shows absence of significant luminal obstruction in the left (A) and right (B) coronary arteries.

병 후 5 일째 퇴원하였다. 퇴원 1 주일 후 시행 한 흥부 방사선 소견 상 양측 폐 영역의 혼탁상은 호전되었다(Fig. 2B). 이상 과 같이 급성 심근경색증과 유사한 임상 양상을 보였지만 심 혈관 조영술 상에서는 정상 소견을 보인 점, 그리고 발병 당시 심초음파 검사에서 좌심실 운동 저하와 좌심실 중벽 및 기저 부의 무운동으로 의심되는 양상을 보인 점 등으로 미루어 $\mathrm{Ta}-$ kotsubo 심근병증으로 진단할 수 있었다. 발병 후 12 개월이 경 과한 현재 특별한 이상 소견 없이 경과 관찰중이다.

\section{고 찰}

Takotsubo 심근병증은 심리적 혹은 신체적 스트레스, epinephrine 등의 외부 요인 등으로 인해 흥통과 심전도 변화가 나타나고, 가역적인 심첨부의 팽대와 심근운동의 저하가 갑자 기 발생하는 가역적 심근병증으로 1990년대 초반에 처음 발견 되었다.") 이 질환은 그동안 일본을 중심으로 동양에서 주로 보 고되었는데, 최근에는 서양에서도 증례가 보고되고 있다. ${ }^{2}$ 이 질환은 급성기 심초음파 영상에 나타나는 심첨부의 모양이 문 어 잡이용 통발(Takotsubo) 모양과 유사해 “Takotsubo 심근 병증이라 명명되었고, Stress cardiomyopathy, Apical ballooning syndrome 등으로도 불린다. ${ }^{5)}$ 직접적인 발병 원인으 로는 정신적 육체적 스트레스, catecholamine의 갑작스런 증 가가 가장 많이 거론되고 있다. ${ }^{4}$ 정확한 병태 생리는 아직 명확
하게 밝혀져 있지 않지만, 혈중 카테콜아민의 급격한 상승에 의한 심독성의 발생, 심장 관동맥의 일시적 경련, 심근 미세혈 관 부전 등으로 추정되고 있다. ${ }^{6}$ 혈중 카테콜아민이 증가되는 크롬 친화 세포종(pheochromocytoma) 환자에서 심근 기능 저하가 동반되는 것도 하나의 예다." 심리적인 스트레스 후 $\mathrm{Ta}-$ kotsubo 심근병증이 자주 유발되는 이유 또한 스트레스시 상 승하는 카테콜아민 때문으로 받아들여지고 있다. ${ }^{6}$ 이러한 카 테콜아민이 어떻게 심근 손상을 일으키는지 그 기전 또한 확 실하지는 않으나, 카테콜아민이 분해되면서 형성된 산소 유리 기에 의해 세포막 및 근세포의 괴사가 일어나거나, 칼슘의 세 포 내 유입에 따라 발생하는 근세포의 과도한 수축이 그 원인 일 것으로 추정되고 있다. ${ }^{5)}$

Takotsubo 심근병증을 진단하기 위해서는 먼저 심초음파 상 에서 일시적인 좌심실 중간 분절의 저운동성, 무운동성, 혹은 이상 운동성, 심첨부 수축 기능의 저하, 심박출량 감소를 확인 해야 한다. 아울러 심전도 상에 ST-분절 상승 혹은 T-파 역전 이 있거나, 심근 효소 troponin의 중등도 상승이 동반되지만, 심혈관 조영술 상 폐쇄성 관상동맥 질환의 증거는 없어야 한다. ${ }^{8)}$ 이처럼 Takotsubo 심근병증은 ST-분절 상승과 troponin-I의 상승이 동반되어 자칫 심근경색증으로 오인하기 쉽지만, 관동 맥 조영술 상 관동맥 폐쇄 병변이 없다는 것이 두 질환의 가장 큰 차이점이다. ${ }^{4)}$ 본 증례에서도 심초음파 상 좌심실의 경미한 저 운동성이 관찰되었고, 심전도 상 ST-분절 상승이 관찰되었 
고, 심근효소의 상승이 있었지만, 혈관 조영술 상 혈관 폐쇄의 증거는 없었다. 이러한 감별진단은 Takotsubo 심근병증 환자 를 대상으로 한 혈전 용해제 사용과 같은 잘못된 치료를 피할 수 있기 때문에 매우 중요하다. Takotsubo 심근병증은 심근경 색증과 달리 여자에서 유병률이 높고, 상대적으로 심근 효소 치의 상승폭이 낮으며, 심근 벽운동의 회복 속도가 매우 빠르 다는 점 또한 구별되는 점이다.9"

Tsuchihashi 등 ${ }^{4}$ 은 Takotsubo 심근병증 환자의 20\%는 정 신적 스트레스가 원인이고, 약 $13 \%$ 는 수술 및 시술이 원인이었 음을 보고하였는데, 이는 수술 중 사용된 카테콜아민의 일종 인 epinephrine 사용과 관련이 있을 것으로 추정된다. 국내에 서도 비강 내 점막에 고농도의 epinephrine 도포 후 심정지가 발생한 증례가 보고된 바 있다. ${ }^{10)}$ Epinephrine은 lidocaine과 혼합하여 이비인후과 영역의 많은 수술에서 국소주사제로 흔 히 사용되고 있다. 그동안 안전 용량을 벗어난 과량 투여, 희석 농도 오류, 주입 방법상의 부주의가 심근에 악영향을 미치는 것으로 알려져 왔다. ${ }^{5)}$ 그런데 허용 범위 안의 epinephrine을 정확하게 국소 주사한 후 심근경색과 유사한 양상을 보이는 Takotsubo 심근병증이 그동안 드물게 보고되어 왔다. ${ }^{2}$ 수술 중 epinephrine 주사나 점적 후 심전도 상 ST-분절 상승이나 T파의 역전, 그리고 QT-간격 연장 같은 변화가 나타나고, 심근 효소인 troponin의 중등도 상승이 동반되면 이 질환의 가능 성을 의심해야 한다. ${ }^{11)}$ 이처럼 안전 용량의 epinephrine 국소 사용에도 심근증이 발생하는 이유는 환자가 epinephrine에 지나치게 민감하거나, epinephrine이 체내에서 과감작 되었거 나, 마취를 위해 사용된 흡입 마취제로 인해 심근이 epinephrine에 더 민감해졌기 때문으로 추정되고 있다. ${ }^{12)}$ 본 증례에서 사용된 epinephrine 총량도 안전 범위를 벗어나지 않았고, 농 도 희석시나 점막 하 주입시 실수가 없었지만 심근병증이 발 생하였다.

Takotsubo 심근병증은 대체로 예후가 좋은 질환으로 알려 져 있다. 사망률은 약 $1 \%$ 이고, 증상은 대부분 2 3일 내에 소실 되고, 좌심실 기능은 1 4주 내에 회복된다는 보고도 있었다. ${ }^{4)}$ 그러나 아직 질병에 대한 병태 생리가 명확히 밝혀지지 않았 기 때문에 환자가 보이는 임상 양상에 따라 대증적인 치료를 하면서, 적절한 혈역학적 지지요법을 시행하는 것이 중요하다. 수술 중 epinephrine 국소 주입 후 혈압 상승과 빈맥이 나타 나면 일단 주의 깊게 혈압과 산소 포화도를 확인하면서 활력 징후의 변화가 소실될 때까지 기다려야 한다. 그러나 빈맥과 고 혈압이 지속되거나 악화되면 일단 혈관 확장제로 혈압을 낮추 어야 한다. 베타 차단제는 오히려 심부전을 유발할 수 있으므 로 주의하여야 한다. ${ }^{13)}$ 심근 기능 저하로 인한 심박출량 감소 와 저혈압이 발생되면 심근 수축제와 승압제의 사용이 필수적
이다. 또 심실 빈맥 발생까지 진행하면 제세동 시행도 고려해 야 한다. ${ }^{14)}$ 폐부종이 동반되면 빈호흡과 함께 수포음을 동반 한 분홍색 거품 양상의 객담을 보이는데, 단순흥부촬영 상 혼 탁상을 보이면 진단할 수 있다. ${ }^{10)}$ 이러한 폐부종 치료를 위해서 는 기계적 환기와 고농도 산소 투여가 필요하고, 이뇨제 사용 등 적절한 약물 치료 또한 필요하다. ${ }^{3)}$

본 증례는 허용 범위 내 epinephrine의 점막 하 주사가 Takotsubo 심근병증이라는 심각한 합병증으로 진행될 수 있음 을 보여주고 있다. 따라서 수술 중에는 수술의와 마취의가 epinephrine 사용에 따른 부작용의 발생 가능성을 항상 염두에 두고 있어야 한다. 부비동 내시경 수술 등 이비인후과 수술 과 정에서 epinephrine을 국소적으로 사용하는 경우에는 우선 적 절한 농도와 용량을 주사하는 것이 무엇보다 중요하다. 비강 내 점막 하에는 혈류가 많고, 흡수가 빠르기 때문에 epinephrine 의 혈중 농도가 빠르게 상승할 수 있기 때문이다. 그러나 epinephrine의 허용 범위 내의 적절한 사용에도 불구하고, 수술 중 갑자기 중등도 이상으로 혈압이 상승하면 지속적으로 혈압, 산 소 포화도, 심전도 등의 변화를 감시해야 한다. 경과 관찰 중 정상 상태로 회복되지 않고, 급성 심근경색증과 비슷한 임상 양상을 보일 경우에는 Takotsubo 심근병증의 발병 가능성을 항상 염두에 두어야 한다. 전신마취 하 수술에서는 epinephrine의 국소적 이용시 마취 의사에게 반드시 미리 통보하여 혈압 등 생체 활력 징후의 변화를 잘 관찰할 수 있도록 해야 한다. 국소 마취 하 수술의 경우 술자는 Takotsubo 심근병증 의 응급 상황에 대처할 수 있는 심폐 소생술 등을 숙지하고 있 어야 하고, 필요한 응급 장비 또한 미리 준비해야 한다. 이 질 환은 수술 중 빨리 발견하고, 적절한 응급조치를 취하면 대부 분 합병증 없이 회복될 수 있는 질환이므로 술 중 Takotsubo 심근병증이 발병할 경우를 대비하여 적절한 치료법을 항상 숙지하고, 발병이 의심되면 적극적으로 대처해야 한다.

\section{REFERENCES}

1) Bonica JJ, Akamatsu TJ, Berges PU, Morikawa K, Kennedy WF Jr. Circulatory effects of peridural block. II. Effects of epinephrine. Anesthesiology 1971;34(6):514-22.

2) Villareal RP, Achari A, Wilansky S, Wilson JM. Anteroapical stunning and left ventricular outflow tract obstruction. Mayo Clin Proc 2001;76(1):79-83.

3) Cho CK, Jung SM, Kim JY, Kwon HU, Kang PS. Stress Induced Cardiomyopathy after Local Epinephrine Use: a case report. Korean J Anesthesiol 2008;54(5):581-4.

4) Tsuchihashi K, Ueshima K, Uchida T, Oh-mura N, Kimura K, Owa $\mathrm{M}$, et al. Transient left ventricular apical ballooning without coronary artery stenosis: a novel heart syndrome mimicking acute myocardial infarction. Angina Pectoris-Myocardial Infarction Investigations in Japan. J Am Coll Cardiol 2001;38(1):11-8.

5) Sato Y, Tanaka M, Nishikawa T. Reversible catecholamine-induced cardiomyopathy by subcutaneous injections of epinephrine solution in an anesthetized patient. Anesthesiology 2000;92(2):615-9. 
6) Kume T, Akasaka T, Kawamoto T, Yoshitani H, Watanabe N, Neishi $\mathrm{Y}$, et al. Assessment of coronary microcirculation in patients with takotsubo-like left ventricular dysfunction. Circ J 2005;69(8):934-9.

7) Imperato-McGinley J, Gautier T, Ehlers K, Zullo MA, Goldstein DS, Vaughan ED Jr. Reversibility of catecholamine-induced dilated cardiomyopathy in a child with a pheochromocytoma. N Engl J Med 1987;316(13):793-7.

8) Prasad A, Lerman A, Rihal CS. Apical ballooning syndrome (TakoTsubo or stress cardiomyopathy): a mimic of acute myocardial infarction. Am Heart J 2008;155(3):408-17.

9) Lee HH, Gwon HC, Kim BJ, Lee KJ, Im ES, Won KH, et al. Clinical manifestation of novel stress-induced cardiomyopathy mimicking acute myocardial infarction: single center prospective registry. Korean Circ J 2002;32(12):1054-63.

10) Chean SM, Lee HJ, Cho SK. Cardiac arrest due to high concentration epinephrine soaking on the nasal mucosa during halothane anesthesia. Korean J Anesthesiol 1992;25(3):627-30.

11) Matsuoka K, Okubo S, Fujii E, Uchida F, Kasai A, Aoki T, et al. Evaluation of the arrhythmogenecity of stress-induced "Takotsubo cardiomyopathy" from the time course of the 12-lead surface electrocardiogram. Am J Cardiol 2003;92(2):230-3.

12) Carter BT, Westfall VK, Heironimus TW, Atuk NO. Severe reaction to accidental subcutaneous administration of large doses of epinephrine. Anesth Analg 1971;50(2):175-8.

13) Lee JY, Kim CH, Lee SJ, Jun NH, Park WK. Acute heart failure induced by a beta-blocker after the local infiltration of epinephrine: a case report. Korean J Anesthesiol 2007;52(5):591-5.

14) Cho JK, Song JK, Choi SJ, Chu YH, Kim DH, Kim JJ, et al. Reversible cardiomyopathy induced by accidental subcutaneous administration of overdose epinephrine. Korean J Med 1996;50(1):130-3. 